\title{
CORRESPONDENGE
}

\section{Screening and Treatment in Retinopathy of Prematurity}

by PD Dr. med. Andreas Stahl and Prof. Dr. med. Wolfgang Göpe

in issue $43 / 2015$ retinopathy of prematurity following iatrogenic doses of erythropoietin $(1,2)$. In addition to the time point at which erythropoietin administration begins, the duration of treatment may be equally relevant-an aspect that was less focused on in the Cochrane Reviews. Work on animal models has shown that erythropoietin administration for retinopathy of prematurity during stages with active pathological angiogenesis can further increase preretinal proliferation, thereby worsening those stages. In contrast, erythropoietin administration that was limited to the very early stages of retinopathy even had a protective effect in the animal models (3). In clinical reality, however, administration of erythropoietin is often frequently repeated and is necessary for prolonged periods of time. Perhaps most relevant to the risk of retinopathy of prematurity might therefore be those administration courses in which erythropoietin is given over longer periods, including during the phase of retinal angiogenic activation (phase II of retinopathy of prematurity).

In general, the aim should be to obtain the best possible postnatal management, which has the main initial goal of ensuring survival of the preterm infant, yet at the same time obtaining the lowest possible rate of stages of retinopathy of prematurity that require treatment. For those stages of retinopathy of prematurity that cannot be adequately controlled despite optimal conditions of systemic factors, it is essential to have a timely detection of indication for an ophthalmological treatment and possibly a targeted therapeutic intervention.

DOI: 10.3238/arztebl.2016.0328b

\section{REFERENCES}

1. Aher SM, Ohlsson A: Late erythropoietin for preventing red blood cell transfusion in preterm and/or low birth weight infants. Cochrane Database Syst Rev 2014; 4: CD004868.

2. Ohlsson A, Aher SM: Early erythropoietin for preventing red blood cell transfusion in preterm and/or low birth weight infants. Cochrane Database Syst Rev 2014; 4: CD004863.

3. Chen J, Connor KM, Aderman CM, Smith LEH: Erythropoietin deficiency decreases vascular stability in mice. J Clin Invest 2008; 118 526-33.

4. Stahl A, Göpel W: Screening and treatment in retinopathy of prematurity. Dtsch Arztebl Int 2015; 112: 730-5.

\section{In Reply:}

We thank the author for commenting on the role that oxygen affinity of fetal hemoglobin could play in the development of retinopathy of prematurity. This aspect must certainly be considered-in addition to numerous other pathomechanistically relevant factors - in the assessment of retinopathy of prematurity.

In this context, we would like to mention a question that is widely discussed at the moment, about the effects of erythropoietin on the risk of retinopathy of prematurity. Two recently published Cochrane Reviews have described an increased risk of developing
PD Dr. med. Andreas Stahl

Klinik für Augenheilkunde, Universitätsklinikum Freiburg andreas.stahl@uniklinik-freiburg.de

Prof. Dr. med. Wolfgang Göpel

Neonatologie, Universitätsklinikum Schleswig-Holstein, Campus Lübeck

\section{Conflict of interest statement}

Prof. Göpel has received travel and accommodation reimbursement and well as honoraria for preparation of scientific meetings from Chiese, AbbVie, and Novartis.

PD Dr. Stahl has received consultant fees, travel and accommodation reimbursement, honoraria for preparation of scientific meetings, and financia support for research (third-party funds) from Novartis 